\begin{tabular}{|c|c|c|}
\hline Beitr. Ent. & Keltern & ISSN 0005-805X \\
\hline $\mathbf{6 2}(2012) 2$ & S. $447-457$ & 20.12 .2012 \\
\hline
\end{tabular}

\title{
Agdistis marionae sp. n., a new Pterophoridae from St. Helena
}

\section{(Lepidoptera)}

With 14 figures

\section{Ernst Arenberger, Annalea M. Beard, Ivar Hasenfuss and Tim Karisch}

\section{Summary}

Agdistis marionae sp. $\mathrm{n}$. is introduced as new species to science. The imago and genitalia are depicted. The chaetotaxie of the larval stadium is done and as graphics pictured.

Key words

Tropical Region, Fauna of St. Helena, Pterophoridae, Agdistis marionae sp. n.

\section{Zusammenfassung}

Agdistis marionae sp. n. wird als neue Art beschrieben. Ihre Imago und Genitalien werden abgebildet. Die Chaetotaxie des Larvalstadiums wird durchgeführt und bildhaft dargestellt.

\section{Introduction}

Because of intensive collecting activities in the bushy stands of Frankenia portulacifolia the collector was successful in finding a lot of specimens of a new Agdistis species on the island of St. Helena, where has not often been collected before. The new species is described as Agdistis marionae sp. n. here. Two localities of the coastal zones, Great Shaking Rocks and Joan Hill, have been examined. In this restricted region Agdistis marionae sp. n. has been found in all stages of development, from larva to imago, and they are all described in this article. We thank Dr. Sabine Gaal-Haszler for the translation of text parts from German into English and for looking through the manuscript.

\section{Abbreviations}

$\begin{array}{ll}\text { Ar. } & \text { Arenberger } \\ \text { Coll. } & \text { Collection } \\ \text { Fig. } & \text { Figure } \\ \text { GU } & \text { Genitalia preparation } \\ \text { NHML } & \text { Natural History Museum London } \\ \text { NHMW } & \text { Naturhistorisches Museum Wien }\end{array}$




\section{Agdistis marionae sp. $\mathbf{n}$.}

Holotype, $0^{*}$ : „St. Helena Island, Manati Bay, Great Shaking Rocks, reared from Frankenia portulacifolia, caterpillars/pupa collected on 30. Dec. 2010, hatched Jan. 2011, leg. Annalea M. Beard“. GU 6451 o Ar. Coll. NHMW (in Coll. Arenberger).

Paratypes: $10^{\star}$ : with the same data as holotype. GU $6468 \sigma^{\star}$ Ar. $10^{\star}$ o : South Atlantic Ocean, St. Helena Island, Great Shaking Rocks, Manati Bay, 31.12.2011, leg. Miss Annalea Beard. GU 6475 i Ar. Barcoding CCDB-11447. Sample MNVD-11447-A08; ơ: Barcoding CCDB11447. Sample MNVD-11447-A07. $10^{\star}$ ㅇ: St. Helena Island, Man and Horse, Joan Hill, reard from Frankenia portulacifolia, January 2011, leg. Annalea M. Beard. GU 6469 o, 6512 ㅇ Ar. $20^{\top} \sigma^{*}$ : South Atlantic Ocean, St. Helena Island, Joan Hill, Man and Horse, 28.12.2011, leg. Miss Annalea Beard. Barcoding CCDB-11447. Sample MNVD-11447-A011. 2 우 ㅇ: ditto. GU 6476 ㅇ Ar. Barcoding CCDB-11447. Sample MNVD-1147-A10. In coll. NHMW (in Coll. Arenberger) and in Coll. NHML.

\section{Etymology:}

The new species is dedicated to Mrs. Marion Rose BEARD, mother of the discoverer of this beautiful Pterophoridae.

\section{Diagnosis (Fig. 10):}

Wingspan: $14-15 \mathrm{~mm}$. Forewings grey brown, from the basis to the area without markings strongly darkened, at the end of the dark area with 2 dots lying one on top of the other. Costaland inner margin a little lighter, but strewn with many dark brown scales. Costal margin with 3 dark dots, the space between whitish. Beneath the first costal dot is another dot. Lower fold margin with two strong patches. Outer margin with light brown basal line, top of the fringe dark brown. Hindwings single-coloured brown. Head, thorax and abdomen dark brown. Thorax tergites with trapeziform white markings. Antennae brown - whitish ringed. Tarsi of hind legs light brown with dark brown ends.

Genitalia, $\sigma^{*}$ (Fig. 6): Valves asymmetrical. Both with a pointed process at a quarter of the inner margin. Left valve at half of its lenght weakly shovel-shaped widened. Right valve small, stripshaped, then nodularly widened and emarginate at the end. Costal arms similar on both sides, with a thin stem and globular end. Tegumen clasp-shaped. Uncus elongate, end with two tips. Caudal margin of sternite 7 roundishly cut, edges of the cutting with short, outwards pointed tip, each. First quarter of aedeagus extremely thin, further course slightly arcuate.

Genitalia, ㅇ (Fig. 8): Antrum strongly sclerotized, cup-shaped, opened wide in caudal direction, ostium convex. From the corners of the antrum, on both sides arises one long, arcuate seta directed to the end of the body. Corpus bursae sack-like. Apophyses anteriores very short, tooth-shaped. Apophyses posteriores bristle-shaped, about twice as long as papillae anales. Sternite 8 deeply cut.

\section{Biological notes:}

The unconcealed larvae and pupae of Agdistis marionae sp. n. were found on plants of the endemic species Fankenia portulacifolia (Rохв.) Sprengel (Fig. 12) growing on dry cliffs at the shore of St. Helena (Great Shaking Rocks (Fig. 11) and Joan Hill, Man and Horse) from December to April. No larvae were found in May. The larvae feed on leaves, rarely on flowers, and prefer large plants of more than $40 \mathrm{~cm}$ height. Duration of the pupal stage is 10 to 12 days under laboratory conditions.

Distribution: Endemic to St. Helena. 


\section{Remarks:}

The new species was compared with all hitherto known Agdistis species from tropical regions. Agdistis marionae sp. n. and the other Agdistis species do not agree. The new species is on no account identical with $A$. santahelenae Wollaston, 1879, which is endemic to St. Helena, too. In $A$. marionae sp. n. it is conspicuous, that there are only two patches at the lower fold margin. Characters, which are only found in $A$. marionae sp. n. Conspicous are the two dots lying one on top of the other at the end of the darkened basal field. In the male genitalia the valves are slimmer than in santahelenae and the end of the right valve is emarginate. In the female genitalia the antrum is widened in caudal direction, the ostium is convex and on both sides arises one sclerotized seta each. In santahelenae the setae are missing and the antrum is cylindrically formed.

\section{Descriptions of larva and pupa of Agdistis marionae sp. n.}

\section{Materials and Methods:}

The descriptions of larva and pupa of Agdistis marionae sp. n. are based on 2 mature and one submature larvae preserved in $70 \%$ ethanol, one ethanol preserved pupa, one desiccated pupa and several pupal exuvia. Morphological observations and illustrations were made with the aid of both compound and stereomicroscopes, and a camera lucida. The terminology of sclerites and the nomenclature of setae and other sensilla follow Hasenfuss \& KRISTEnsen, 2003. The description refers to the left side of the body.

For comparisons, the as yet unpublished findings on the larva and pupa of Agdistis tamaricis (Zeller, 1847) from Tour de Valat (Camargue/South France), reared from eggs on Tamarix spec. were noted in brackets, when the characters were different from those of Agdistis marionae.

Mature larva (Figs 1-3, 13):

General. Unconcealed living larval type, length ca. $12 \mathrm{~mm}$, head width $0.8 \mathrm{~mm}$, antenna and mouthparts directed ventrally. The dorsal part of the head and nearly the whole surface of the body (including the unsclerotized coxae of the thoracic legs) exhibit densely arranged granules (Fig. 2C, D). The larva has only the regular general pattern of setae and other sensilla, no irregular setae are present. Most dorsal and lateral setae are more or less stout, club-like or flattened, and pressed to the body surface (Fig. 2C, D).

The dorsal part of the prothorax (T1) is hood-like extending over the head. Prominent fingerlike dorsal projections are on the thoracic segments T1 and T2. Segment T1 exhibits two projections, the anterior one bears seta XD1 and the posterior the seta D2; a small wartlike elevation bears XD2 (T1- Fig. 2A). The large finger-like projection of T2 bears the setae D1 and D2 (T2-Fig. 2A); the corresponding projection on T3 is smaller (T3-Fig. 2A). In the submature instar, the dorsal projections of T1 and T2 are small, not larger than on T3. Small wart-like elevations are located, on the abdominal segments A1-A9, at the sites of D1, D2, and less distinct at the site of SD1 (Fig. 2A). On A9, the warts of D1 and D2 are fused and form together with the corresponding warts of the opposite side an unpaired flat unity (Fig. 2B). [The dorsal projections of $A$. tamaricis are different in the following characters: the large fingerlike projection on T2 bears three setae (D1, D2 and SD2); the corresponding projection on T3 and the prothoracic projections XD1 and D2 are small, wart-like; a small unpaired wart-like elevation without setae is located dorsally at the anterior margin of T2; on A2, A5 and A8, the separated warts of D1 and D2 are elongated to small finger-like projections; the unpaired wart of A9 is large and finger-like]. 
Color pattern: Head capsule dark brown, frontal side less dark. Body light yellowish green with a white line along the lateral sides (stigmatale) which is more or less interrupted in the posterior region of the segments. White larger vertically elongated spots are laterally on the prominent dorsal projections of segment T2 and T3. In darker specimens a line of blackish spots are dorsally applied to the white line/spots, especially pronounced in the interruptions of the stigmatale. The cuticular granules appear as white or light colored small dots on a darker background. The white especially densely arranged ones are composing the white spots.

Head (Fig. 1)

Head capsule (Fig. 1A-C) with deep epicranial notch, the ecdysial line laterad of AF-setae is missing, the capsule splits upon ecdysis to pupa closely along the inverted Y-sulcus, puncture $\mathrm{Pb}$ absent. 6 stemmata present. Seta G1 long (in A. tamaricis microscopical). - Antenna (Fig. 1G): with the complete general pattern of sensillae. - Labrum (Fig. 1D): lateral margin well sclerotized, not widened antero-laterally, only one puncture (in A. tamaricis, the lateral sides are membranous and antero-laterally widened, 2 punctures). Epipharynx (Fig. 1E): the 3 scale-like sensilla arranged in a straight line. Mandible (Fig. 1F): only with marginal teeth, on the lateral side one puncture and one seta present (in $A$. tamaricis, on the median side with a conspicuous dentate ridge). - Maxilla (Fig. 1I): palpus maxillaris 4-segmented, its median lobe without the row of 3 ventral sensilla. - Labium (Fig. $1 \mathrm{H}$ ): prementum ventrally with a small seta and 2 punctures, the dorsally located palpus labial reduced to a single long seta (p), 2 punctures on the base of the spinneret.

\section{Thorax and abdomen (Fig. 2)}

Tergal shields on $\mathrm{T} 1$ and A10 absent. The spiracles are slightly elevated on a conical peritrema (sp- Fig. 2A). Pinacula of setae inconspicuous.

Segments of the thoracic legs: Coxa unsclerotized, seta Cx8 absent (Fig. 3A). The sole seta $T 1$ and no punctures present on the trochanter (Fig. 3B), the trochanter is as usual only partly separated from the femur by a membranous strip. In contrast to coxa and trochanter, all setae of the general pattern are present on femur, tibia and tarsus (Fig. 2B-D).

Prolegs with crochets arranged in a median uniordinal penellipse, gradually smaller towards both ends (Fig. 2E). The number of crochets are 13, 14/15, 17/18, 20/21 and ca. 23 on segments A3, A4, A5, A6 and A10, respectively.

Chaetotaxy of the thoracic (T1, T2, T3) and abdominal (A1-A10) segments (Fig. 2A, B): No microscopical setae were found on T1. All other microscopical setae are present with the exception of MV2 on T2 and T3 (all present in A. tamaricis). MSD1 is without a discernible shaft (well visible in $A$. tamaricis); MD1 is on A8 in the unusual position just below D1 (Fig. 2B). From the normally 6 prothoracic tactile setae and 3 punctures dorsal from the spiracle, only 4 setae were detected, their homologies are somewhat uncertain (T1 - Fig. 2A). The prespiracular L-group on T1 is unisetose. V1 is absent on the thoracic segments. YANO, 1963 and WASSERTHAL, 1970 figured V1 in their setal maps as present on the thorax in Pterophoridae. Contrary to this, Hasenfuss (unpubl. observations) stated the absence of V1 on segment T1, T2 and T3 not only in Agdistis marionae sp. n. but also in Agdistis tamaricis, Agdistis bennetii (CurTis, 1833), Pterophorus pentadactylus (Linnaeus, 1758), Emmelina monodactyla (Linnaeus, 1758), and an Oxyptilus spec. Segments T2 and T3 are identical except for the fact, that the common wart of D1 and D2 is much smaller on T3 than on T2 (Fig. 2A).

On A1-A8, the setae L1 and L2 are widely separated, L3 being unisetose (two L3-setae in A. tamaricis on A1-A6, the anterior one in some distance before the other). On A9, only L1 and L3 are present, L2 is missing. The SV-group on T2/T3 is bisetose. SV3 is present on the 
abdominal segments A1-A8 and SV2 only on A3-A6. (SV3 is absent on A8 in A. tamaricis). An additional dorsal seta (D2) is present on A10, its pair is located between and somewhat behind the pair of D2 (Fig. 2B). On the ventral part of A10 no punctures were found, and setae AL1 and AL4 are missing. (A. tamaricis differs in having in the AL-group, the full set of 5 setae and one puncture).

\section{Pupa (Figs 4, 5, 14):}

Length ca. $9 \mathrm{~mm}$. The surface of the head, thorax and appendages is uneven, partly sculptured with granules (Fig. 4B below); the surface of A1-A9 is armed with small spinules. A9 bears ventrally an unpaired rounded bulge or prominence (ub -Fig. $4 \mathrm{~A}, \mathrm{C}$ ). Segment A10 is short, stout, and not elongated; the spinules are modified to small hooked spines (not setae!) especially on the dorsal and (less numerous) on the lateral surface (Fig. 4C); the ventral surface and the region around the anus are without such spines. [In other Pterophoridae, the segment is elongated, gradually tapering to the end and form ventrally together with A9 an oblique plane. The lateral and posterior margin of the plane bears hooked spines; an additional group of such spines is located mid-ventrally on A9 at the margin of a rounded prominence (HASENFuss unpublished observations, see Mosher, 1916, YANO, 1963). The prominence is supposedly the homologue of the similar smoth strucure up in Fig. 4A, C of the present species. Apparently, the marginal hooked spines of A10 are likewise homologous with the dorsal and lateral spines of Agdistis marionae sp. n.]. The spiracles on T2 and A2-A7 are functional, on A1 covered by the wings, and on A8 collapsed (Fig. 4B, C). Nearly all larval setae are maintained in the pupa (as in other Pterophoridae, see Yano, 1963), even the form is the same as in the larva. - The pupa is lightly colored with few dark spots (Fig. 4B): a curved line at the base and the margin of the fore wings, a line on the corner of the hind wings, a line or spot below the spiracle on A3-A6 and a small subdorsal spot in A3-A6.

The pupa is attached to a twig with the dorsal side (!) of its last abdominal segment (Fig. 5). The attachment is due to the dorsal hooked spines which are hooking to a web made by the larva before pupation. Since, the larva and hence its exuvium always cling to a twig with its prolegs on the ventral side, the attachment of the pupa is inverse. During ecdysis, both the larval had capsule and the thoracic cuticle remain on the ventral side of the end of the pupal abdomen. More posteriorly, the exuvium is twisted so that the crochets of the prolegs remain hooked to the web at the twig. It may be that during this processes the pupa hangs at the exuvium by the cuticle of the proctodaeum and hooks itself into the web by wriggling and rotating the abdomen thus causing the $180^{\circ}$ turn of the pupa around its length axis and twisting the exuvium. All three, the anterior part of the exuvium, the end of the pupa, and the twig are glued together by a hardened secretion. [The pupa of $A$. tamaricis is attached to the side of a twig by hooking the marginal hooked spines of the ventral plane of A9 and A10 to a small web (Hasenfuss, unpublished observation)].

\section{References}

Arenberger, E. 1995: Pterophoridae 1. Teilband. - In: Amsel, H. G.; Gregor, F. \& Reisser, H.: Microlepidoptera Palaearctica 9. - Karlsruhe, Verlag Braun: I-XXV., 258 S., 153 Taf.

Hasenfuss, I. \& Kristensen, N. P. 2003: 5. Skeleton and muscles: immatures. - In: Kristensen, N. P. (ed): Volume IV; Arthropoda: Insecta, Part 36 Lepidoptera, moths and butterflies, vol. 2 Morphology, physiology and development. - Berlin, New York, Walter de Gruyter: p. 133-164.

Mosher, E. 1916: A classification of the Lepidoptera based on characters of the pupa. - Bulletin of the Illinois Laboratory Natural History 12: 17-159, pls. 19-27. 
Wasserthal, L. 1970: Generalisierende und metrische Analyse des primären Borstenmusters der Pterophoriden-Raupen (Lepidoptera). Eilarven als Objekte systematischer Untersuchungen. - Zeitschrift für Morphologie der Tiere 68: 177-251.

YANo, K. 1963: Taxonomic and biological studies of Pterophoridae of Japan (Lepidoptera). - Pacific Insects 5: 65-209.

Author's addresses:

ERnst Arenberger

Naturhistorisches Museum Wien

Burgring 7, 1010 Wien

Österreich

E-Mail: ernst.arenberger@chello.at

Dr. Ivar Hasenfuss

Karlsbader Str. 9E

91083 Baiersdorf

Deutschland

E-Mail: IHasenfuss@t-online.de
Subject editor:

Annalea M. Beard

Dr. R. Gaedike

Heathfield, Dewlands Common

Verwood, Dorset

England BH31 6JL

TIM Karisch

Museum für Naturkunde und Vorgeschichte Dessau

Askanische Straße 32

06842 Dessau, Deutschland

E-Mail:Tim.Karisch@naturkunde.dessau.de

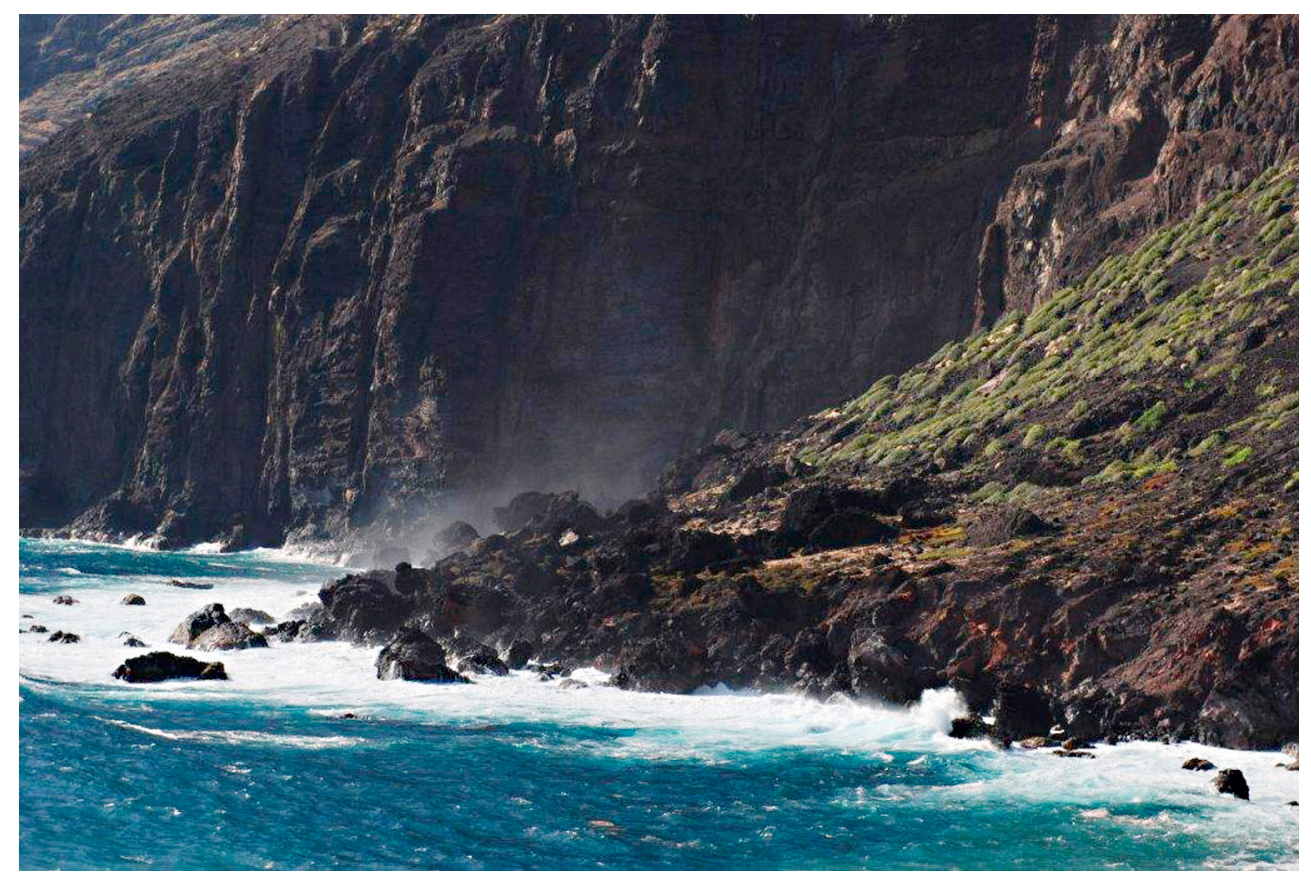

Fig. 11: St. Helena, Great Shaking Rocks. 

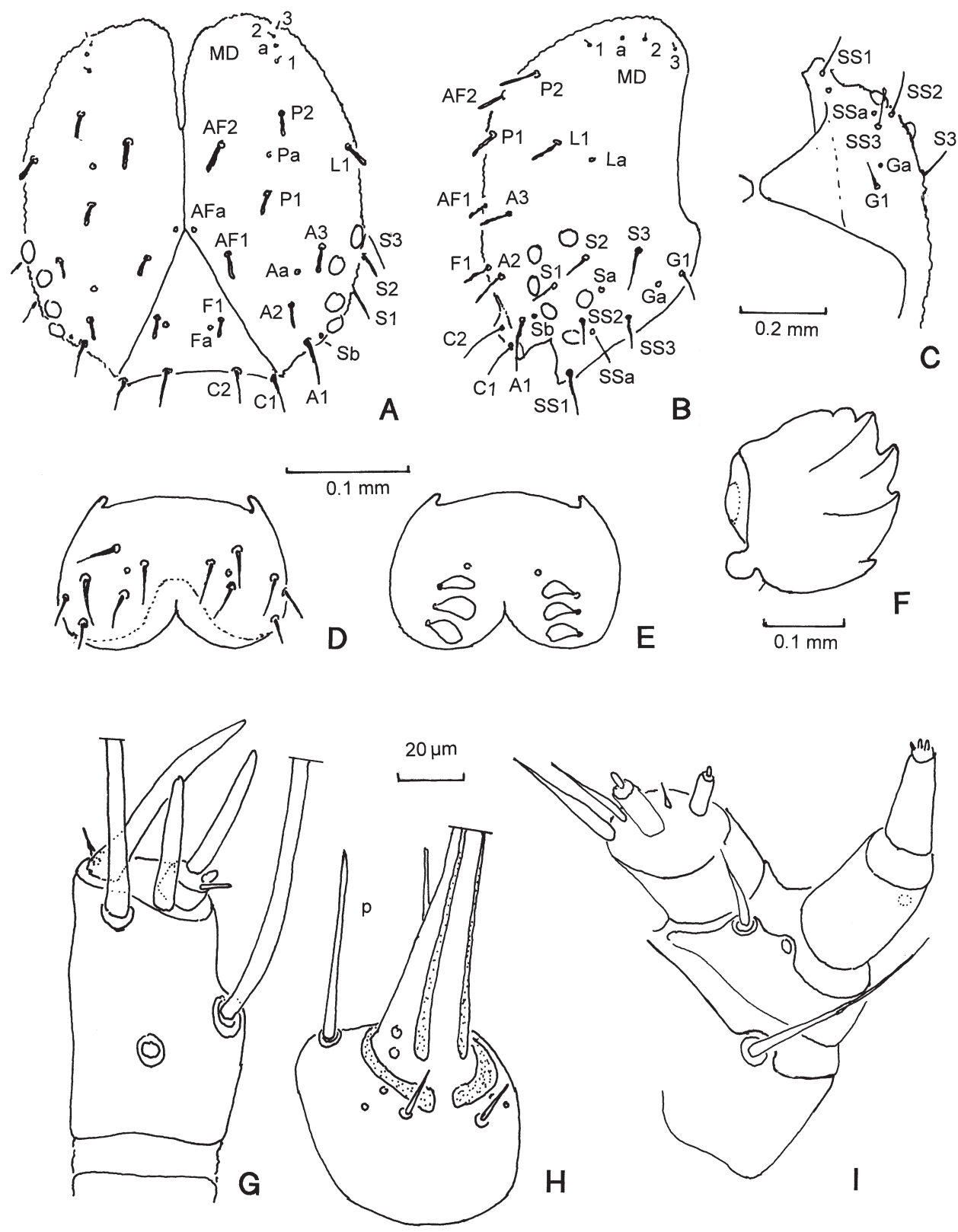

Fig. 1: Setae and other sensilla of the larval head of Agdistis marionae. A-C: head capsule, frontal (A), lateral (B), ventral (C) view. D: labrum. E: epipharynx. F: left mandible, median view. G: left antenna, ventral view. $\mathrm{H}$ : left palpus maxillaris (4 segments) with the median lobe, medio-ventral view. I: praementum of the labium with the spinneret base, ventral view. 

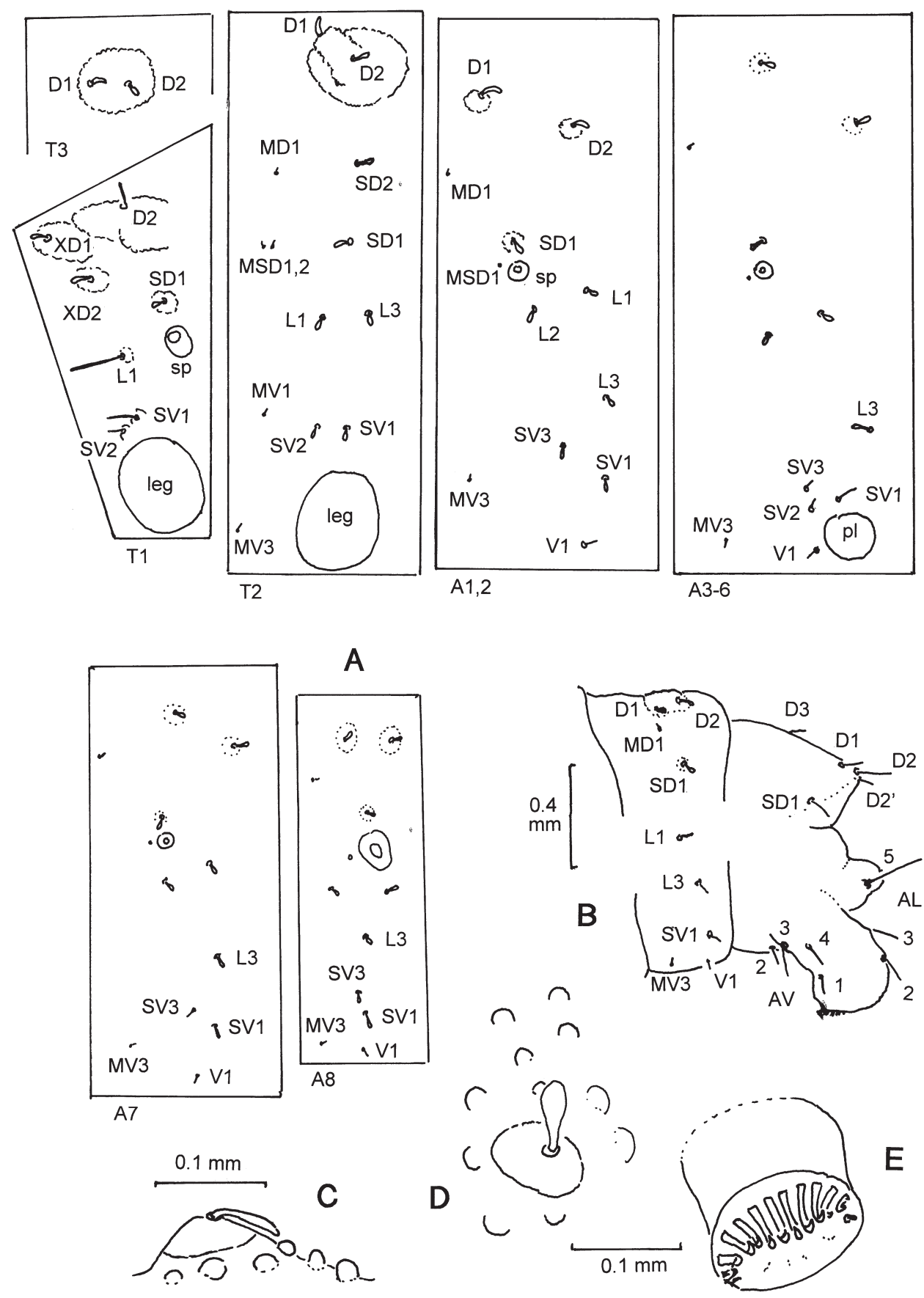

Fig. 2: Cuticular structures of the postcephalic body of Agdistis marionae. A: setal maps of the segments of thorax T1-T3 and abdomen A1-A8. B: abdominal segments A9 and A10, lateral view. C: seta D1 on A3, lateral view. D: seta D1 on A3, dorsal view. E: right proleg of A3, median view, anterior side at left. $\mathrm{sp}$ - spiracle, $\mathrm{pl}$ - proleg. 

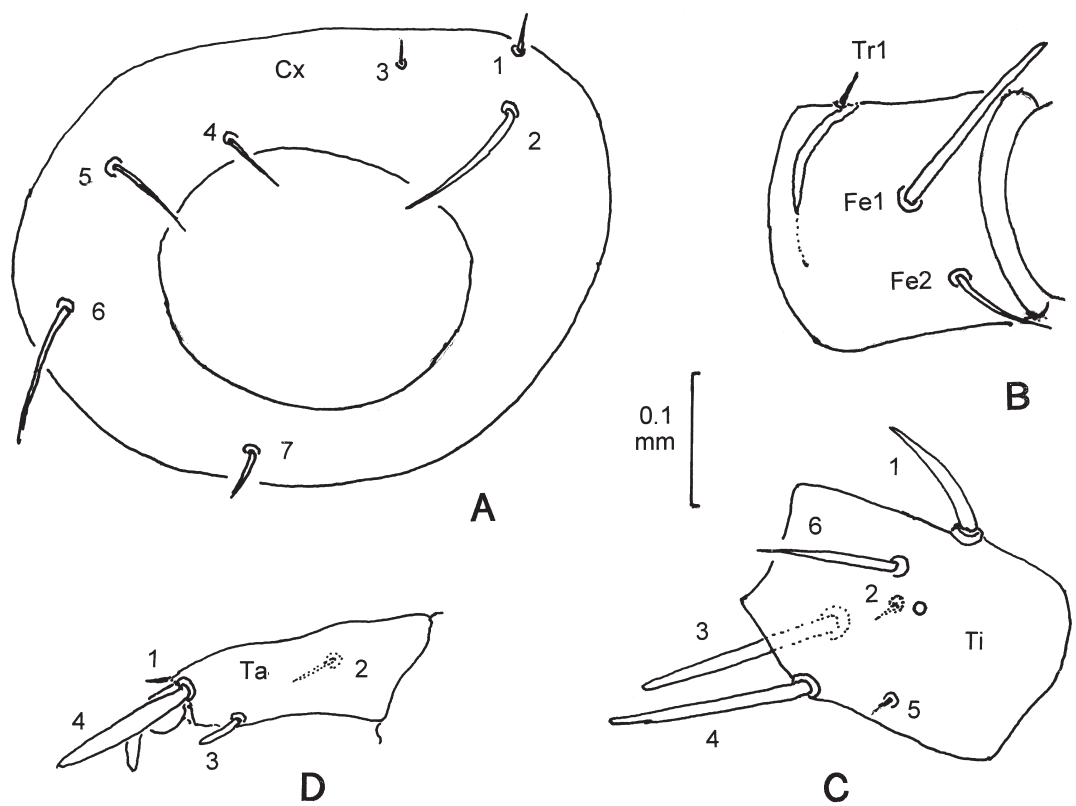

Fig. 3: Sensilla of the left mesothoracic leg of Agdistis marionae; setae of the opposite side and a membranous strip punctuated. A: coxa, ventral view, anterior margin above, median side left. B: trochantero-femur, ventral view, distal end at right. C: tibia, posterior view, proximal end at right. D: tarsus with pretarsal claw, posterior view.
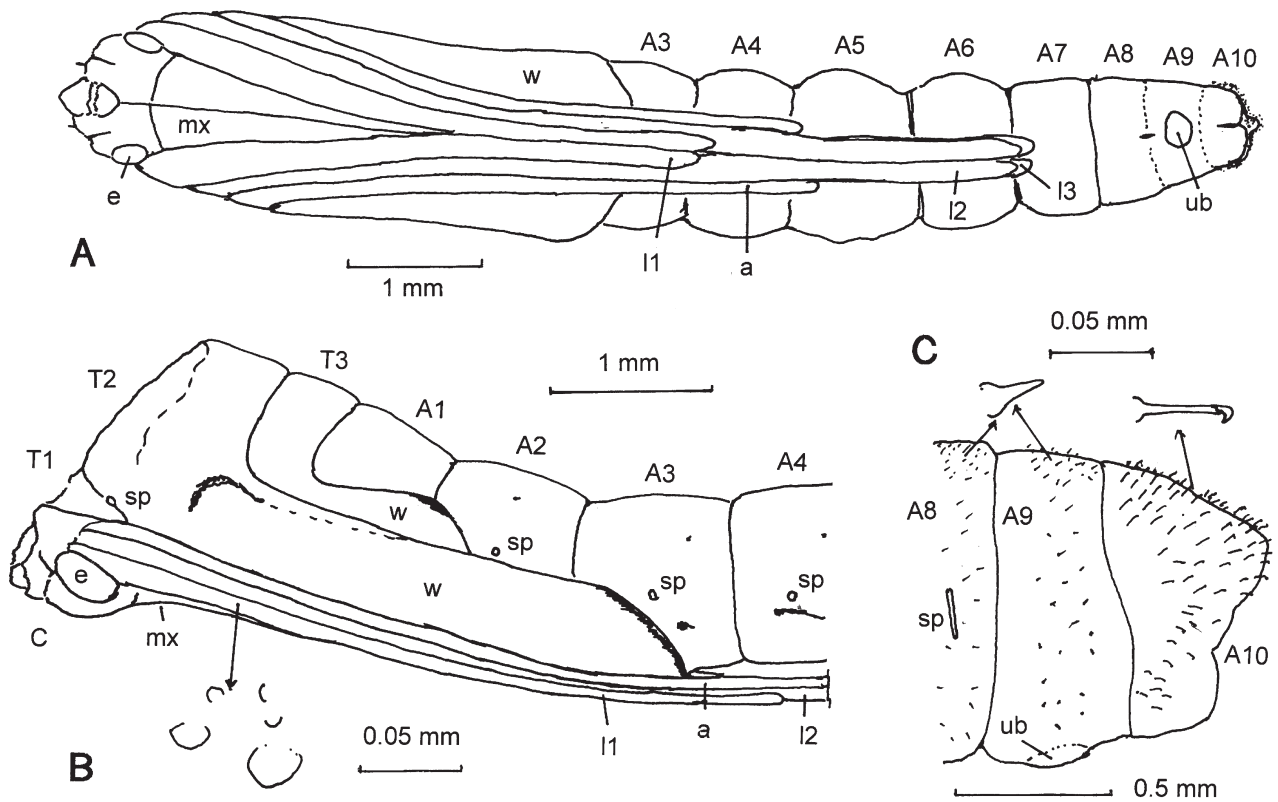

Fig. 4: Female pupa of Agdistis marionae. A: ventral view. B: left side of head, thorax and 4 basal abdominal segments; below granules of thorax. C: left side of abdominal segments 8-10; above spinules of the abdominal segments 1-9 (left) and elongated hooked spines on A10. A1-A10 - abominal segments; e - eye; 11-3 - thoracic legs; sp - spiracle; $\mathrm{mx}$ - maxilla; $\mathrm{ub}$ - unpaired bulge; $\mathrm{w}$ - wing. 


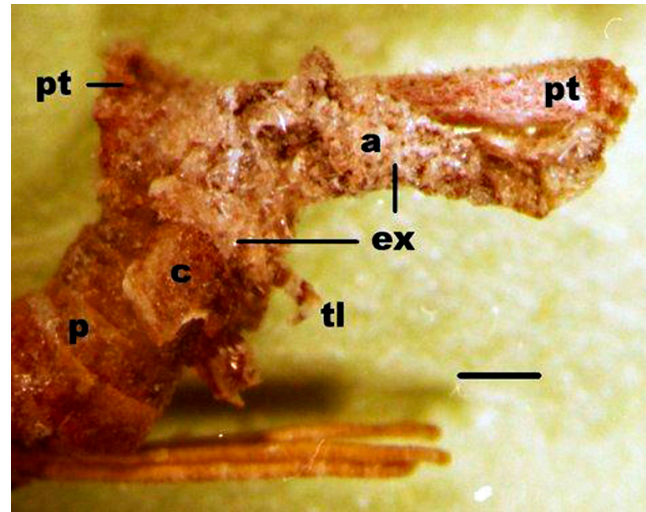

Fig. 5: Attachment of a desiccated pupa (p) of Agdistis marionae at a plant twig (pt); $\mathrm{a}=$ abdomen, $\mathrm{c}=$ head capsule, and $\mathrm{tl}=$ thoracic leg of the exuvium (ex). The brown color is due to postmortal darkening. Scale $0.5 \mathrm{~mm}$.

Figures 1-5: at disposal by I. HaSENFuss.

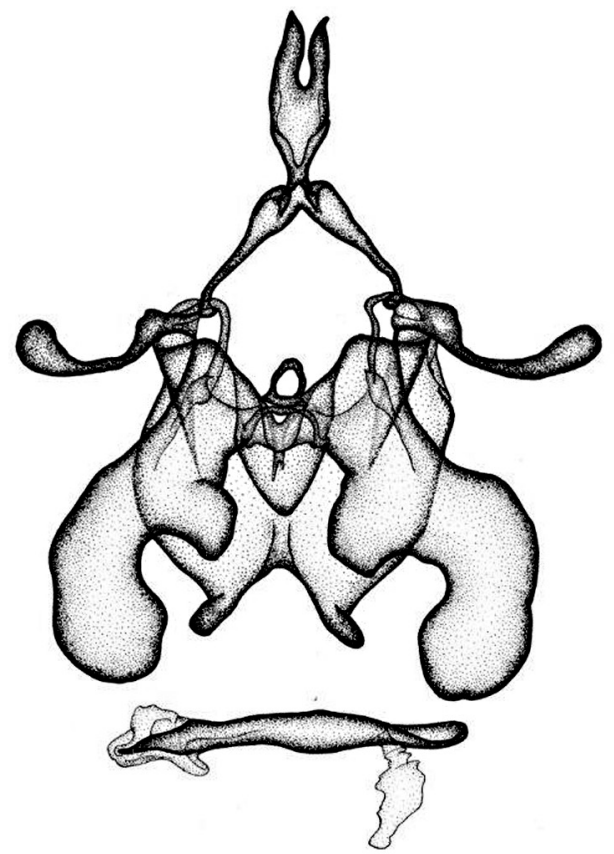

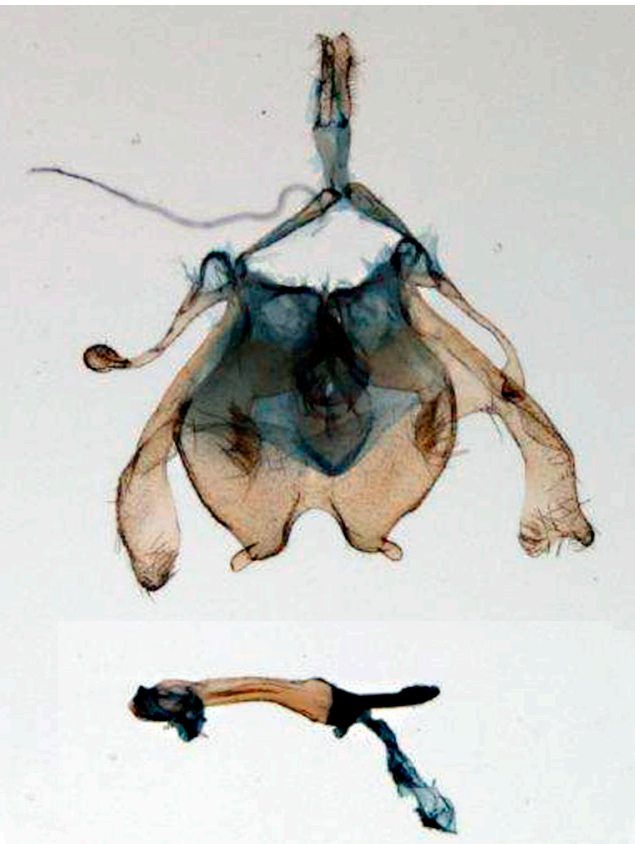

Fig. 6: Male genitalia of Agdistis marionae sp. n.

Fig. 7: Male genitalia of Agdistis santahelenae Wollaston. Fig. 8: Female genitalia of Agdistis marionae sp. n. 


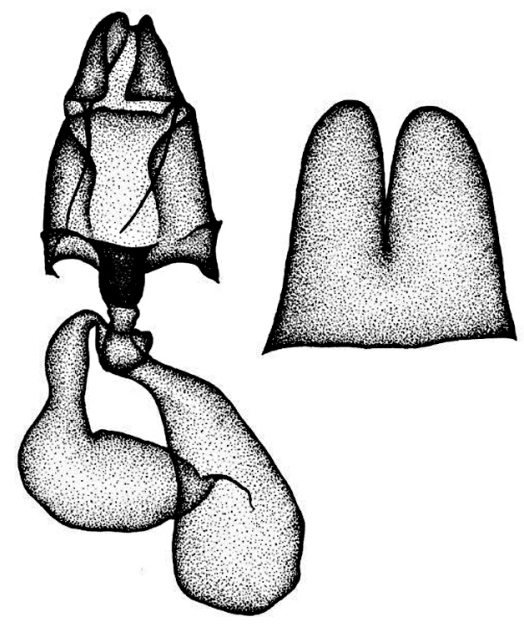

Fig. 9: Female genitalia of Agdistis santahelenae WOLLASTON.

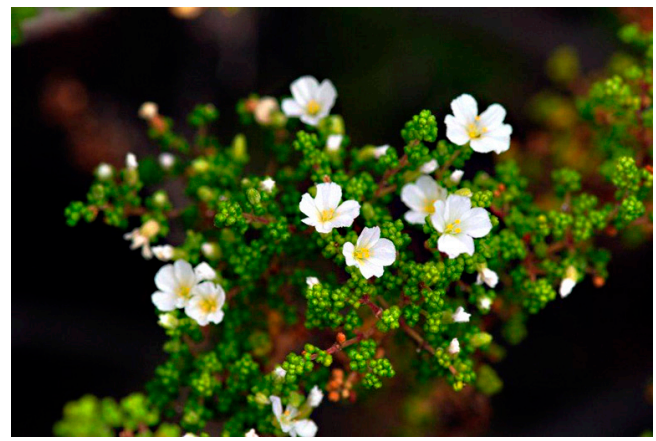

Fig. 12: Frankenia portulacifolia.

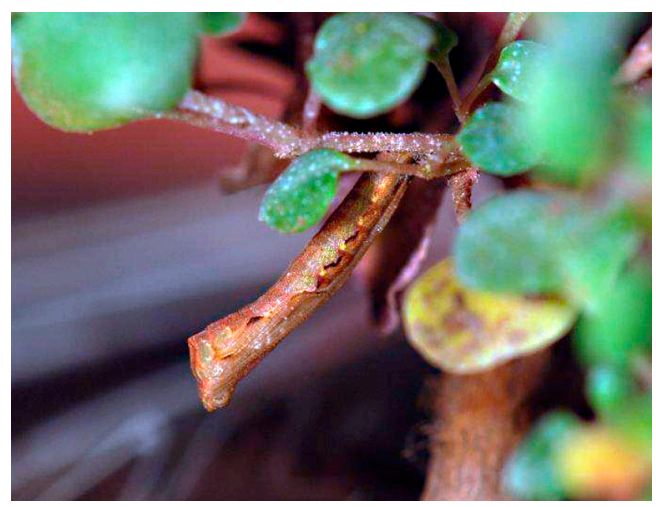

Fig. 14: Pupa of Agdistis marionae sp. n.

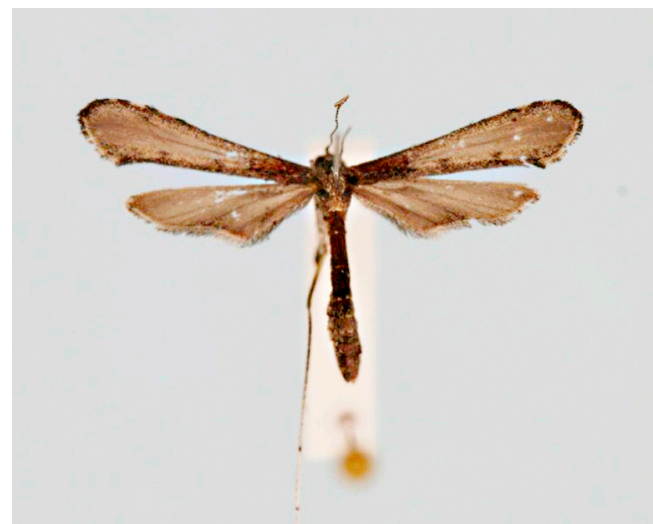

Fig. 10: Imago of Agdistis marionae sp. n.

Figs 6-10: put at disposal by E. Arenberger. Figs 7 and 9 published in Arenberger, 1995.

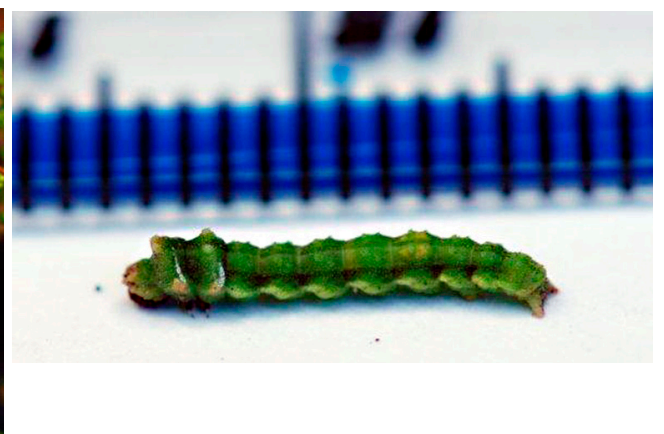

Fig. 13: Caterpillar of Agdistis marionae sp. $\mathrm{n}$.

Figs 11-14: put at disposal by A. BEARD. 